\title{
Molecular strategies for gene containment in transgenic crops
}

\author{
Henry Daniell \\ University of Central Florida, Department of Molecular Biology and Microbiology, 12722 Research \\ Parkway, Orlando FL 32826-3227
}

\section{Abstract}

The potential of genetically modified (GM) crops to transfer foreign genes through pollen to related plant species has been cited as an environmental concern. Until more is known concerning the environmental impact of novel genes on indigenous crops and weeds, practical and regulatory considerations will likely require the adoption of gene-containment approaches for future generations of GM crops. Most molecular approaches with potential for controlling gene flow among crops and weeds have thus far focused on maternal inheritance, male sterility, and seed sterility. Several other containment strategies may also prove useful in restricting gene flow, including apomixis (vegetative propagation and asexual seed formation), cleistogamy (selffertilization without opening of the flower), genome incompatibility, chemical induction/deletion of transgenes, fruit-specific excision of transgenes, and transgenic mitigation (transgenes that compromise fitness in the hybrid). As yet, however, no strategy has proved broadly applicable to all crop species, and a combination of approaches may prove most effective for engineering the next generation of GM crops.

Concerns about the environmental impact of GM crops currently limit their widespread acceptance. Many of these concerns focus on the premise that such transfer could potentially result in the emergence of "superweeds" that are resistant to herbicides or the introduction of undesired traits into related crop plants. A discussion of data concerning the ability of specific GM plants to hybridize with sexually compatible species is beyond the scope of this review. However, it is clear that gene flow depends on several variables: the specific crop, its location, the presence of outcrossing wild relatives/sexually compatible crops, the competitive nature (advantages and disadvantages) of the introduced trait, and the environmental consequences of neutral traits. Two mechanisms are responsible for the movement of genes among crops and their wild relatives/related crops: dispersal in viable pollen or dissemination in seed (that later germinates and produces viable pollen).

The potential for gene flow through pollen depends on such variables as the amount of pollen produced, longevity of pollen, dispersal of pollen (as by wind or animals), plant/weed density, dormancy/rehydration of pollen, survival of pollen from toxic substances secreted by pollinators, the distance between crops and weeds, and whether these plants are sexually receptive to the crop.

Following pollination and reproduction, dispersal of seeds from GM plants may also occur among weedy relatives during harvest, transportation, planting, and reharvest, giving rise to mixed populations. If these GM seeds germinate, grow, and reproduce, there is a risk that interbreeding with a sexually compatible weedy species could produce a fertile hybrid. Additional crossing with the weed species (introgressive hybridization) could then result in 
new weeds that have acquired the GM trait. This again depends on the persistence of the crop among weeds and probability of forming mixed stands.

With the availability of current molecular technologies, the opportunity exists to alter gene flow by interfering with flower pollination, fertilization, and/or fruit development. In the following review, I discuss the various technologies currently under development for addressing gene flow among crops and weeds. In each case, I summarize the limitations and efficacy of the approach based on the available data (see Table 1).

\section{Maternal inheritance}

Maternal inheritance of cytoplasmic organelles is shared by plant (chloroplasts) and animal (mitochondria) systems. Several explanations have been offered to explain this phenomenon. It promotes the invasion of a population by selfish cytoplasmic factors that are overrepresented within an individual ${ }^{1}$. In addition, maternal inheritance of cytoplasmic factors is an evolutionary mechanism to prevent sexual transmission of disorders or pathogens associated with males; only the nucleus (not cytoplasm) is allowed to penetrate the ovule during fertilization ${ }^{2}$. It may also be an extension of the general suppression of male nuclear genes that takes place in plants after fertilization ${ }^{3}$.

The use of chloroplast genetic engineering to promote maternal inheritance of transgenes is highly desirable in those instances involving a potential for outcross among GM crops or between GM crops and weeds. The prevalent pattern of plastid inheritance found in the majority of angiosperms is uniparental-maternal and chloroplast genomes are maternally inherited in most crops. However, there are exceptions: species such as tobacco have been reported to have $\sim 0.1-0.5 \%$ pollen transfer of chloroplast traits ${ }^{4}$, and paternal inheritance has been noted in a few higher plants ${ }^{5,6}$ (although these reports are several decades old and should be reexamined using modern tools). Furthermore, triazine resistance (conferred by the mutant chloroplast $p s b A$ gene) is also paternally inherited in rare instances (such inheritance is $<0.5 \%$ and requires examination of large sample sizes and semidominant nuclear markers ${ }^{2}$ ).

Maternal inheritance of the chloroplast genome is achieved in plants during the development of the generative cells that form sperm cells, which then fuse with the female gametes during fertilization. The generative cells are the result of unequal divisions during pollen formation and do not receive any chloroplasts ${ }^{7}$. In some species, chloroplast DNA is degraded during generative and sperm cell formation, resulting in physical exclusion of chloroplast DNA during sexual fusion.

Maternal inheritance of transgenes and prevention of gene flow through pollen in chloroplast transgenic plants have been successfully demonstrated in several plant species, including tobacco and tomato ${ }^{8,9}$. Although chloroplast genomes of several other plant species, including potato, have been transformed, maternal inheritance has not been demonstrated in these studies. However, more than 30 transgenes have been stably integrated into chloroplast genomes to confer desired plant traits or for the use of transgenic chloroplasts as biofactories to produce functional biopharmaceuticals or edible vaccines or biopolymers ${ }^{10,11}$.

Unlike many other containment strategies, the maternal inheritance approach has already been tested in the field. Scott and Wilkinson ${ }^{12}$ studied plastid inheritance in natural hybrids collected from two wild populations growing next to oilseed rape along $34 \mathrm{~km}$ of the Thames River in the United Kingdom and assessed the persistence of 18 feral oilseed rape populations over a period of three years. They analyzed several variables that would influence the movement of chloroplast genes from crops to wild relatives, including the 
mode of inheritance of plastids and incidence of sympatry (the occurrence of species together in the same area), to quantify opportunities for forming mixed populations and persistence of crops outside agriculture limits for introgression. Despite some 0.6-0.7\% sympatry between the crop and weed species, mixed stands showed a strong tendency toward rapid decline in plant number, seed return, and ultimately extinction within three years. Thus, Scott and Wilkinson concluded that gene flow should be rare if plants are genetically engineered via the chloroplast genome.

In addition to its potential for gene containment, chloroplast engineering offers several other advantages. For example, gene expression from the chloroplast confers tissue specificity, occurring predominantly where functional plastids are located. For situations in which the target pests feed mainly on leaves rather than roots, the presence of transgenic plastids and high levels of insecticidal protein in leaf tissue may be highly beneficial. This technique is also valuable when using leaves as biofactories for foreign protein manufacture. It is also possible to engineer multiple genes via the chloroplast genome in a single transformation event ${ }^{13}$ and to use antibiotic-free selectable markers ${ }^{14}$. Chloroplast genetic engineering avoids the position effects and gene silencing that are often observed in nuclear transformation, as well as harmful transgene products that cause pleiotropic effects; all of these problems can be overcome by compartmentalization within plastids ${ }^{10,11}$.

Thus, maternal inheritance of chloroplast genomes is a promising option for gene containment. Although plastid transformation remains to be achieved in several major crop species, chloroplast genetic engineering has now been shown to confer resistance to herbicides $^{8}$, insects ${ }^{15}$, disease ${ }^{16}$, and drought ${ }^{17}$, as well as to produce antibodies ${ }^{10}$, biopharmaceuticals ${ }^{10}$, and edible vaccines ${ }^{18}$. A recent report from the European Environment Agency (Copenhagen, Denmark) recommends chloroplast genetic engineering as a gene-containment approach ${ }^{19}$.

\section{Male sterility}

Interfering with the development of reproductive structures in crops through mutagenesis or genetic engineering is another strategy for interrupting gene flow. There are many points in the pollination/fertilization process that could be targeted for intervention (see Fig. 1).

Thus far, studies have focused on interfering with the anther, the plant's male reproductive organ that produces pollen grains containing sperm cells. The tapetum is one of several specialized cell/tissue types composing the anther that surrounds the pollen sac in early development, but is not present as an organized tissue in the mature anther. It is thought to have an important function in the formation of pollen, in that it synthesizes several proteins that aid in pollen development or become components of pollen.

Many male-sterility mutations interfere with tapetal cell differentiation and/or function, indicating that this tissue is essential for the production of functional pollen. Mariani et al. ${ }^{20}$ have exploited this feature, using the $5^{\prime}$ region of a tobacco tapetum-specific gene (TA29) to drive expression of recombinant $\beta$-glucuronidase or ribonuclease genes (RNase T1 and barnase) within the tapetal cells of transgenic tobacco and oilseed rape plants. Expression of RNase genes selectively destroys the tapetum during anther development, preventing pollen formation and producing male-sterile plants.

Male sterility is also the basis of the Barstar Barnase system used in the Plant Genetic Systems (Ghent, Belgium) glufosinate (Bar-gene)-tolerant rapeseed. In this system, cauliflower mosaic virus (CaMV) 35S promoter-directed expression of the ribonuclease barnase from Bacillus amyloliquefaciens inhibits pollen formation and results in male sterility of the transformed plants. Linkage of the barnase gene with the (Streptomyces 
hygroscopicus) bar marker gene, which encodes a phosphinothricin acetyltransferase enzyme that inactivates glufosinate, permits identification of the male-sterile line before crops begins to flower. GM rapeseed containing the Barstar Barnase system compose $~ 10 \%$ of the commercially cultivated crop in Canada and is one of the few GMOs cleared for agricultural use in Europe.

These two examples suggest that male sterility, induced by destruction of the tapetum by transgene-encoded ribonucleases, could allow gene containment. However, while interfering with pollen development may be effective in preventing gene flow in many cases, under exceptional circumstances it is possible that a GM crop engineered to be male-sterile could be fertilized by pollen from wild relatives and serve as a female parent for hybrid seed. If this hybrid were to survive, germinate, grow, and reproduce, it could produce viable pollen containing the GM trait that could cross-pollinate weeds.

One possible advantage of male-sterility strategies is that they could be used to enhance the shelf-life of many flower species (Easter lilies, roses, and carnations), because fertilization initiates the process of floral degeneration and fruit set. Several promoters are now under development that can be induced by the application of exogenous chemicals ${ }^{2}$ (see later). For crops (e.g., oilseed rape) in which intervarietal introgression must be eliminated, such promoters could be used to switch ribonucleases on or off, creating fertility restorer mechanisms that would make pollen infertility reversible ${ }^{21}$. Alternatively, the crop could be propagated by cross-pollination from a nontransgenic crop or by artificial seed (somatic embryos or transgenic parthenocarpy-i.e., fruit without seeds). It is important to note that such strategies may pose significant logistical problems for producers and farmers.

\section{Seed sterility}

Genes in the embryo and endosperm involved in seed formation and germination may also be targeted to achieve gene containment. One way of accomplishing this is with a system dubbed "terminator technology," which was patented several years ago by the United States Department of Agriculture (USDA; Germantown, MD), Cornell University (New York, NY), Purdue University (West Lafayette, IN), and Iowa State University (Ames, IA), and licensed to Delta \& Pine Land Seed Company (Scott, MS), which was subsequently bought by Monsanto (St. Louis, MO).

Although little has been published in the scientific literature describing the technology, Odell et al. ${ }^{22-24}$ outline the components of the seed-suicide mechanism, which is triggered by a specific exogenous stimulus, such as the antibiotic tetracycline (temperature or osmotic shock can also be used). Using the "Tet on"repressor system, the site-specific recombinase Cre is induced and excises a "spacer" sequence, bounded by lox sites, between the cytotoxic ribosome-inhibitor protein (RIP), which is under the control of the seed-specific late embryonic abundance ( $L E A$ ) promoter. In the absence of tetracycline-induced Cre, the spacer acts as a safety catch to prevent RIP from being activated. When tetracycline is applied to the seed before sale, Tet repression is suppressed and the recombinase gene is switched on. Cre removes the spacer, allowing expression of RIP to proceed from the $L E A$ promoter and resulting in the specific destruction of seed tissues. Another variant, described in a patent by Tomes ${ }^{25}$, uses a similar strategy to manipulate tryptophan synthesis so that abnormal levels of the plant hormone auxin indole acetic acid (IAA) are induced. Elevated levels of IAA lead to seed abortion and sterility.

Koivu et al. ${ }^{26}$ have also described a system termed "recoverable block of function" (RBF). The RBF system consists of a "blocking" sequence linked to the transgene of interest and a recovering sequence, all in one transformable construct. In nature, hybrids of transgenic plants with their wild relatives carrying the RBF die or are unable to reproduce because of 
the action of the blocking construct. In tobacco, for example, a transgene can be linked to barnase (blocking construct) under the control of a germination-specific promoter (e.g., the vacuolar cysteine proteinase sulfhydryl endopeptidase (SH-EP)), and barstar (recovering construct) under the control of a heat-shock promoter. Under natural conditions, the recovering construct does not act because the heat-shock promoter is not induced and the seeds are made sterile. Fertility can be restored by inducing the heat-shock promoter through temperature or osmotic shock.

There are several drawbacks to the terminator system. First, it is important that all three genes (encoding Cre, RIP, and Tet) remain linked together. If during reproduction they do not segregate together and the Tet repressor passes on to one plant while Cre and RIP pass on to another, all the seeds produced by the latter plant would commit suicide. Though of low likelihood, it is important that the GM trait of interest is physically linked to the terminator construct, otherwise a recombination event could disrupt the linkage. Second, it will be difficult to ascertain whether all the seeds treated with the tetracycline inducer have triggered the gene switch (i.e., whether tetracycline has penetrated all of the seeds). And third, the $L E A$ promoter may be subject to silencing. Even if $L E A$-silenced seeds were treated with tetracycline, Cre expressed, and the spacer sequence excised, no RIP would be produced at the end of the life cycle, and there would be a possibility for introgression of a GM trait.

\section{Cleistogamy and apomixis}

Progress in understanding the molecular basis of processes that control flowering, especially in such systems as Arabidopsis and Antirrhinum spp., may also open up the possibility of manipulating genes involved in flower development to engineer crops with reduced risk of gene transfer.

In certain plants, self-pollination and fertilization occurs with the flowers remaining unopened-a process termed cleistogamy. It has been suggested that crops engineered to exhibit cleistogamy would have a minimal risk of gene spread. Very little work has thus far focused on this approach, and our knowledge of genes in flower development remains rudimentary. Thus, although several genes involved in flower development have recently been identified in model plants, including APETALA and $L E A F Y$, identification of genes that could be useful for engineering the cleistogamy phenotype remains remote. An additional limitation of this approach is that even if cleistogamy could be engineered into certain crops carrying a GM trait, it might prove ineffective. In rice that exhibits cleistogamy, for example, genes readily move between cultivated and feral forms of weedy rice, despite predominant self-pollination.

Another option would be to engineer crops to produce seeds without fertilization. This process, termed apomixis, occurs naturally in a few plant species. In apomixis, the seed is actually of vegetative origin and not produced from sexual pollination. Because many apomictic plants produce no viable or compatible pollen, it is possible that the method could be used to create GM plants with reduced risk of gene transfer without compromising seed or fruit production. The apomictic embryo is formed in the ovule through sporophytic (from the integument or nucellus) or gametophytic (from the megaspore mother cells or nucellar cells) pathways. Irrespective of origin, generation of fertile seeds can be dependent on fertilization for the formation of endosperm. However, autonomous apomicts develop an endosperm independently of fertilization of polar nuclei. Apomixis fixes a maternal genotype, because the male gametophyte makes no contribution to the genetic makeup of the embryo and meiosis is not necessary. Therefore, in addition to gene containment, this process is very helpful to fix a superior plant variety. Apomixis has already been employed 
to achieve hybrid vigor without sexual crosses ${ }^{27}$. However, it is known to occur only in a few cultivated crops. Koltunow et al. ${ }^{27}$ discuss various molecular strategies for the generation of genetically identical seeds without fertilization, including isolation of genes controlling the apomictic process and transferring this trait to a much wider variety of crop species.

\section{Genome incompatibility}

Many cultivated crops have multiple genomes. Only one of these crop genomes is compatible for interspecific hybridization with weeds. For example, the D genome of wheat is compatible with the $\mathrm{D}$ genome of Aegilops cylindrica (bearded goatgrass), a problem weed in the United States; in contrast, it would be much harder to achieve interspecific hybridization of the weed with durum wheat, which has an AABB tetraploid B genome ${ }^{2}$, provided ploidy level is not an issue. Similarly, there is possibility for gene transfer from the B genome of Brassica juncea (Indian or brown mustard) to many Brassica weeds with wild species; however, thus far most genetic engineering has been carried out Brassica napus, which has the AACC tetraploid genome and is thus unlikely to be compatible. The risk of transgenic traits spreading into weeds can be reduced drastically by releasing only those transgenic lines with incompatible genomes. However, the approach is not likely to work in all crops.

In general, much more information is required to determine the genes responsible for compatibility of weeds and specific crops. With the availability of such information, it might become possible to engineer crops that have a reduced likelihood of outcrossing with weeds through incompatibility mechanisms. It will also be important to assess the fertilities of interspecific and intraspecific hybrids of crops and weeds on a case-by-case basis. Of course, although genome compatibility approaches might provide a solution to gene flow from a GM crop, they also raise the problem of how one would cross-pollinate the GM crop itself if no sexually compatible weed or related crop were available nearby.

\section{Temporal and tissue-specific control}

Chemically inducible promoters may also prove to be a useful tool for gene containment strategies. For example, a chemical could be used to induce transient expression of a gene conferring herbicide resistance before a field is sprayed with herbicide ${ }^{2}$. Clearly, genetic isolation may be possible by restricting expression of a foreign gene to those times when the crop is not flowering. Although several such promoters are currently available (see ref. 28), on the whole most inducible systems are not yet ready for commercialization (an exception might be Syngenta's (Greensboro, NC) alcohol dehydrogenase system). In addition, the approach may not be applicable for traits, such as insect or pathogen resistance or production of a biopharmaceutical, that may need to be present throughout the life cycle of a transgenic plant. Nevertheless, such a system may prove useful for crops with GM traits that are required only for specific time periods.

An alternative approach to switching on a foreign gene only when a crop is not in flower would be physically to remove the gene before flowering occurs. Keenan and Stemmer ${ }^{29}$ suggest that this could be achieved by using chemically inducible or fruit-specific promoters to activate expression of a site-specific recombinase, such as Cre, that would excise a foreign gene before flowering. Such systems would induce Cre expression and result in the removal of a gene flanked by two lox sites in either the seed (using a seed-specific promoter) or the entire plant (using a chemically inducible promoter).

Practical application of chemical inducers or tissue-specific promoters for gene containment will require resolution of several problems. For example, incomplete penetration of plant 
reproductive tissues by the chemical inducer could lead to residual levels of target genes. Transient expression using inducible promoters (rather than chemically induced excision) would also not physically remove foreign genetic material from the GM crop seed. In the system of Keenan and Stemmer, the presence of residual lox $P$ sequences after excision would also present a problem for regulators that discriminate against GM material and non$\mathrm{GM}$ material in the food chain (extraneous $\operatorname{lox} P$ sequence is unlikely to have deleterious ecological consequences). Finally, continued presence of foreign proteins with long halflives, even after removal of foreign genes, may also present problems for regulators who discriminate on the basis of process.

\section{Transgenic mitigation}

Another approach for containing gene spread would be to compromise the fitness of weeds that by introgression have acquired positive survival traits from crop genes ${ }^{30}$. This approach, termed transgenic mitigation (TM), is based on the premises that (1) tandem constructs act as tightly linked genes, and their segregation from each other is exceedingly rare; (2) TM traits are neutral or positive for crops, but deleterious for weeds; and (3) even mildly harmful TM traits will be eliminated from weed populations because such plants compete strongly among themselves and have a large seed output. Examples of processes that might be targeted by TM include seed dormancy, seed ripening and shattering, and growth.

Weed seeds typically exhibit secondary dormancy, with those from one harvest germinating throughout the following season and in subsequent years, thereby maximizing fitness (and preventing all weeds from being controlled by single treatments) while reducing sibling competition. Abolition of secondary dormancy is neutral to the crop, but deleterious to weeds. Steber et al. ${ }^{31}$ have identified an Arabidopsis mutant that is insensitive to abscisic acid and totally lacks secondary dormancy. If this or similar genes associated with dormancy could be identified/engineered or mutated, it might be possible to achieve TM by using this approach.

Another characteristic of weedy plants is that they disperse their seeds over a period of time, and most of their ripe seeds shatter to the ground, ensuring continuity. As a result, uniformly ripening and antishattering genes are harmful to weeds but neutral for crops, whose seeds ripen uniformly and do not easily shatter; in fact, anti-shattering genes are even advantageous for oilseed rape, which still has shattering and volunteer weed problems. Only weed-free "certified"seed is sown, thereby eliminating transgenic weed seed. Although the details of the process are still unclear, it is thought that the changing hormone balance in the abscission zone of a seed influences shattering propensity. Cytokinin overproduction may delay shattering. A SHATTERPROOF gene has been recently isolated from Arabidopsis that prevents seed shattering by delaying valve opening on the silique ${ }^{32}$. This may be an ideal strategy for the closely related oilseed rape.

Dwarfing has been especially valuable in generating "green revolution" varieties of rice and wheat and brought self-sufficiency to India and China. However, the dwarfing trait is disadvantageous for weeds, because they can no longer compete with the crop for light. Genetically engineered height reduction is possible by preventing biosynthesis of gibberellins ${ }^{33}$. In addition, a defective gibberellic acid receptor gene has been isolated that confers gibberellin instability by competing with the native receptor, thereby inducing dwarfing ${ }^{34}$.

Putting the TM approach (whatever trait is used) into practice will require considerable effort. This is because organizing tandem constructs of tightly linked nonsegregating genes will require multigene engineering. In addition, this approach does not address gene flow 
from a GM crop to other crops or to wild relatives that are not considered weeds and "need" to be protected from "genetic contamination" for biodiversity.

\section{Conclusions}

There is currently a paucity of data on the environmental impact of specific GM traits. Nevertheless, it is likely that for the near future, regulatory restrictions will dictate that genecontainment systems will have to be developed for future GM crop releases. At present, no effective gene-containment method is available for all GM crops, and considerable investment and research are needed to develop the technologies outlined earlier.

This review has summarized a selection of molecular approaches that have potential for gene containment. It has not attempted to discuss the use of spatial and temporal management systems to minimize gene flow, such as "isolation zones" (i.e., areas between GM crops and other crops that are de-vegetated or planted with a non-insect-pollinated crop that discourages insect pollinators from leaving a GM crop), "crop barriers" (a non-GM crop planted around the borders of the same GM crop that serves to dilute GM pollen, increase the distance that GM pollen has to travel to outcross, and buffer the GM crop in the center from foraging insect pollinators), or other types of vegetation barriers. Clearly, such approaches will have to take into account changing weather and environmental conditions that might promote long-distance pollen dispersal ${ }^{19}$. For a certain number of years following harvest, land-use restrictions may also be necessary to allow monitoring, removal, and destruction of plants arising from volunteer seeds.

It is clear that the characteristics of seed and pollen production, dispersal, and potential outcrossing must be determined for each specific crop in each specific environment. Different crop species have different rates of autogamy and outcrossing, and some crops have hybridizing wild relatives only in certain geographic locations. It will also be important to allay concerns that crops engineered with altered pollination, flowering, or male-sterility patterns for the purpose of gene containment will not affect the wider biodiversity of insects, birds, and other wildlife in existing ecosystems.

If molecular approaches are to become more powerful, effort must be directed toward determining the contribution and coordination of structural and regulatory genes involved in the formation of pollen, pollen germination, and production of embryo and endosperm in crops. At present, the identity of many key seed- and pollen-specific genes remains unknown, and the role of epigenetic processes, such as chromatin remodeling and DNA methylation, in imprinting is unclear.

As described earlier, several biological containment measures have been developed to control gene flow through pollen or seed. Some are more advanced than others. Male sterility has already been commercially exploited in canola. It is very effective at preventing outcrossing from GM crops to weeds or related non-GM crops. However, seeds produced from male-sterile GM crops by cross-pollination from weeds may pose problems, because seeds of such hybrids will produce fertile pollen that would carry the GM trait. Also, pollen is not produced in a crop that makes the seed, making it less desirable for the farmer because it would require either cross-pollination from a non-GM crop or propagation by artificial seed. Maternal inheritance is a promising approach for transgene containment, with added advantages of high levels of transgene expression, rapid multigene engineering, lack of position effects, and gene silencing. Currently, chloroplast genetic engineering has been shown to be efficacious in tobacco as a bioreactor for production of biopharmaceuticals, monoclonals, or biopolymers or to confer desired plant traits. It has been used in potato and tomato to confer desired plant traits or to accomplish oral delivery of biopharmaceuticals or 
edible vaccines. However, this technology should be extended to all major crops if it is to reach its full potential.

Seed-sterility technology is still at the exploratory stage. The terminator technology should be tested in the field. Unresolved questions remain about proper segregation of multiple genes, consequences of gene silencing, and the presence of transgenic pollen. Such questions may be resolved by field tests. Cleistogamy or apomixis do not present these disadvantages, but genes are not readily available for engineering these traits into desired crops. Strategies for genome incompatibility may effectively block outcrossing or seed production. Paradoxically, in such approaches fertile seeds would have to be produced by artificial pollination of crops because no sexually compatible feral or non-GM crops or weeds will be around. Chemically inducible promoters are useful only for traits that are transiently required (such as herbicide resistance). Excision of genes using chemically inducible fruit-specific promoters is a better option, provided such treatment is complete to avoid any residual effect. Transgenic mitigation, unfortunately, does not address gene flow between crops or preserve biodiversity. None of these approaches has been tested in transgenic crops.

It is clear that no single strategy will be suitable for all crops and that a combination of the aforementioned approaches will be necessary for effective transgene containment. It is encouraging to note that most biotechnology companies are engaged in research and development to improve the next generation of GM crops, utilizing these new approaches.

\section{Acknowledgments}

The author is grateful to the editor of Nature Biotechnology, Andrew Marshall, for valuable contributions and thorough editing of this manuscript. The author also thanks Jonathan Gressel (Weizmann Institute of Science, Rehovot, Israel) for providing an advance copy of the material in the forthcoming book Molecular Biology in Weed Control, Jeremy Sweet (NIAB, Cambridge) for critical comments, and Chuck Niblett (University of Florida, Gainesville, FL) for editing the manuscript.

\section{References}

1. Hurst LD. Cytoplasmic genetics under inbreeding and outbreeding. Proc. Royal Soc. London B. 1994; 258:287-298.

2. Gressel, J. Molecular Biology in Weed Control. Taylor and Francis; London: 2002.

3. Vielle-Calzada JP, Baskar R, Grossniklaus U. Delayed activation of the paternal genome during seed development. Nature. 2000; 404:91-94. [PubMed: 10716449]

4. Avni A, Edelman M. Direct selection for paternal inheritance of chloroplasts in sexual progeny of Nicotiana. Mol. Gen. Genet. 1991; 225:273-277. [PubMed: 2005869]

5. Corriveau JP, Coleman AW. Rapid screening method to detect potential biparental inheritance of plastid DNA and results for over 200 angiosperm species. Am. J. Botany. 1988; 75:1443-1458.

6. Tilney-Bassett, RAE.; Abdel-Wahab, OAL. Maternal effects and plastid inheritance. In: Newth, DR.; Balls, M., editors. Maternal Effects in Development. Cambridge University Press; Cambridge: 1979. p. 29-45.

7. Hagemann R, Schroeder M. The cytological basis of plastid inheritance in angiosperms. Protoplasma. 1989; 152:57-64.

8. Daniell H, Datta R, Varma S, Gray S, Lee SB. Containment of herbicide resistance through genetic engineering of the chloroplast genome. Nat. Biotechnol. 1998; 16:345-348. [PubMed: 9555724]

9. Ruf S, Hermann M, Berger IJ, Carrer H, Bock R. Stable genetic transformation of tomato plastidshigh-level foreign protein expression in fruits. Nat. Biotechnol. 2001; 19:870-875. [PubMed: 11533648]

10. Daniell H, Khan MS, Allison L. Milestones in chloroplast genetic engineering: an environmentally friendly era in biotechnology. Trends Plant Sci. 2001; 7:84-91. [PubMed: 11832280] 
11. Daniell H, Dhingra A. Multiple gene engineering: dawn of an exiting new era in biotechnology. Curr. Opin. Biotechnol. 2002; 13:136-141. [PubMed: 11950565]

12. Scott SE, Wilkinson MJ. Risks of transgene escape from transplastomic oilseed rape. Nat. Biotechnol. 1999; 17:390-392. [PubMed: 10207890]

13. DeCosa B, Moar W, Lee SB, Miller M, Daniell H. Overexpression of the Bt Cry2Aa2 operon in chloroplasts leads to formation of insecticidal crystals. Nat. Biotechnol. 2001; 19:71-74. [PubMed: 11135556]

14. Daniell H, Muthukumar B, Lee SB. Engineering the chloroplast genome without the use of antibiotic selection. Curr. Genet. 2001; 39:109-116. [PubMed: 11405095]

15. Kota M, et al. Overexpression of the Bacillus thuringiensis Cry2A protein in chloroplasts confers resistance to plants against susceptible and Bt-resistant insects. Proc. Natl. Acad. Sci. USA. 1999; 96:1940-1845.

16. DeGray G, Smith F, Sanford J, Daniell H. Expression of an antimicrobial peptide via the chloroplast genome to control phytopathogenic bacteria. Plant Physiol. 2001; 127:852-862. [PubMed: 11706168]

17. Lee SB, Byun MO, Daniell H. Accumulation of trehalose within transgenic chloroplasts confers drought tolerance. Transgenic Res. 2002 in press.

18. Daniell H, Lee SB, Panchal T, Wiebe PO. Expression and assembly of the native cholera toxin B subunit gene as functional oligomers in transgenic tobacco chloroplasts. J. Mol. Biol. 2001; 311:1001-1009. [PubMed: 11531335]

19. Eastham, K.; Sweet, J. Environmental Issue Report 28. European Environmental Agency; Copenhagen, Denmark: 2002. Genetically Modified Organisms (GMOs): The Significance of Gene Flow Through Pollen Transfer.

20. Mariani C, DeBeuckeleer M, Trueltner J, Leemans J, Goldberg RB. Induction of male sterility in plants by a chimaeric ribonuclease gene. Nature. 1990; 347:737-741.

21. Hall LM, et al. Pollen flow between herbicide-resistant Brassica napus is the cause of multiple resistant B. napus volunteers. Weed Sci. 2000; 48:688-694.

22. Odell, JT. Site specific recombination in plant cells. WO 91/09957. 1991.

23. Odell JT, Hoopes JL, Vermerris W. Seed-specific gene activation mediated by the Cre/lox sitespecific recombination system. Plant Physiol. 1994; 106:447-458. [PubMed: 7991679]

24. Russell SH, Hoopes JL, Odell JT. Directed excision of a transgene from the plant genome. Mol. Gen. Genet. 1992; 234:49-59. [PubMed: 1495484]

25. Tomes, DT. Genetic constructs and methods for producing fruits with very little or diminished seed. WO 97/40179. 1997.

26. Koivu K, Kanerva A, Pehu E. Molecular control of transgene escape from genetically modified plants. Plant Sci. 2001; 160:517-522. [PubMed: 11166439]

27. Koltunow AM, Bicknell RA, Chaudhury AM. Apomixis: molecular strategies for the generation of genetically identical seeds without fertilization. Plant Physiol. 1995; 108:1345-1352. [PubMed: 12228546]

28. Jepson, I. Inducible herbicide resistance. WO 97/06269 (EPO 0843730). 1997.

29. Keenan RJ, Stemmer WPC. Nontransgenic crops from transgenic plants. Nat. Biotechnol. 2002; 20:215-216. [PubMed: 11875408]

30. Gressel J. Tandem constructs: preventing the rise of superweeds. Trends Biotechnol. 1999; 17:361-366. [PubMed: 10461182]

31. Steber CM, Cooney SE, Mccourt P. Isolation of the GA-response mutant sly1 as a suppressor of ABI1-1 in Arabidopsis thaliana. Genetics. 1998; 149:509-521. [PubMed: 9611170]

32. Lilegren SJ, et al. SHATTERPROOF MADS-box genes control seed dispersal in Arabidopsis. Nature. 2000; 404:766-770. [PubMed: 10783890]

33. Webb SE, Appleford NEJ, Gaskin P, Lenton JR. Gibberellins in internodes and ears of wheat containing different dwarfing alleles. Phytochemistry. 1998; 47:671-677.

34. Peng J, et al. "Green revolution" genes encode mutant gibberellin response modulators. Nature. 1999; 400:256. [PubMed: 10421366] 


\section{Definitions}

Apomixis Formation and development of an embryo without the fusion of male and female gametes. The embryo is usually formed from the unfertilized egg.

Cleistogamy Self-fertilization without opening of the flower.

Hybrid The interbreeding of two genetically distinct varieties of plant to form offspring. Hybrid plants ( $F_{1}$ hybrids) frequently are more vigorous than their parents and are valued in horticulture.

Introgression The insertion of the genes of one species into the gene pool of another. This can occur when two species interbreed to produce fertile hybrids. These can then back-cross with individuals of one of the parent species.

Outcrossing The mating of unrelated sexually compatible plants, thus introducing the genes of one species into the gene pool of another.

Sympatry The occurrence of species together in the same area.

Volunteer Seed that escapes harvest and remains in the soil until the following season(s), when it germinates either before or following the seeding of the succeeding crop. 


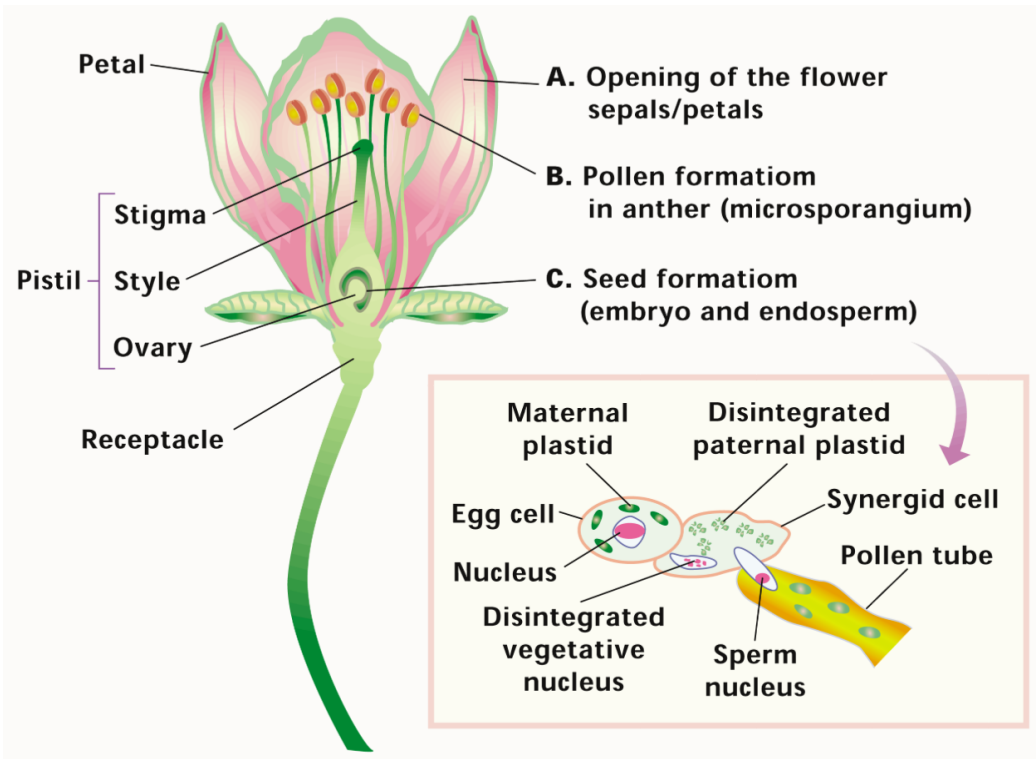

Figure 1.

Potential strategies for restricting gene flow. (A) By restricting flower opening and floral development (cleistogamy) in a GM crop, pollen dispersal and outcrossing could be prevented, thereby mitigating gene flow. (B) Gene flow through pollen could be restricted via chloroplast engineering, male-sterility approaches (including tapetum-specific excision of transgenes), and genome incompatibility. (C) Gene flow through seeds could be restricted by seed-sterility approaches (including seed-specific excision of transgenes) and apomixis. 
Table 1

Current and future technologies for transgene containment ${ }^{a}$

\begin{tabular}{|c|c|c|c|}
\hline Technique & Advantages & Disadvantages & Status \\
\hline Maternal inheritance & $\begin{array}{l}\text { Prevents gene flow through outcrossing } \\
\text { and } \\
\text { volunteer seeds. Relatively well } \\
\text { developed. } \\
\text { Field tests indicate low incidence of } \\
\text { sympatry } \\
\text { and mixed stands extinct in three years. } \\
\text { High } \\
\text { levels of transgene expression and no } \\
\text { evidence } \\
\text { for gene silencing or position effects. }\end{array}$ & $\begin{array}{l}\text { Techniques to export proteins are not } \\
\text { yet available. Foreign proteins have not } \\
\text { been targeted to ER for glycosylation. }\end{array}$ & $\begin{array}{l}\text { Demonstrated in tobacco, } \\
\text { potato, and tomato. } \\
\text { Further development } \\
\text { required to extend to } \\
\text { other food crops. }\end{array}$ \\
\hline Male sterility & $\begin{array}{l}\text { Prevents outcrossing. Shelf-life of } \\
\text { flowers may } \\
\text { also be extended. Several tapetum- } \\
\text { specific } \\
\text { promoters available. }\end{array}$ & $\begin{array}{l}\text { Crop needs to be propagated by cross- } \\
\text { pollination from non-GM crop or by } \\
\text { artificial seeds. Potential for volunteer } \\
\text { seed dispersal. }\end{array}$ & $\begin{array}{l}\text { Demonstrated in tobacco } \\
\text { and commercialized in } \\
\text { glufosinate-tolerant } \\
\text { rapeseed. }\end{array}$ \\
\hline Seed sterility & $\begin{array}{l}\text { Controls both outcrossing and volunteer } \\
\text { seed } \\
\text { dispersal. }\end{array}$ & $\begin{array}{l}\text { If transgene is silenced, introgression } \\
\text { will occur. All linked genes should } \\
\text { segregate together. }\end{array}$ & $\begin{array}{l}\text { Terminator technology has } \\
\text { not been demonstrated in the } \\
\text { field. RBF demonstrated in } \\
\text { tobacco. }\end{array}$ \\
\hline Cleistogamy & $\begin{array}{l}\text { Pollination occurs before flower opens, } \\
\text { theoretically preventing outcrossing. }\end{array}$ & $\begin{array}{l}\text { Genes to modify floral design not } \\
\text { readily available. In practice, } \\
\text { introgression occurs despite } \\
\text { self-pollination. }\end{array}$ & $\begin{array}{l}\text { Not yet demonstrated in } \\
\text { transgenic crops. }\end{array}$ \\
\hline Apomixis & $\begin{array}{l}\text { Seed is of vegetative origin and not from } \\
\text { sexual } \\
\text { cross. Controls both outcrossing and } \\
\text { volunteer } \\
\text { seed dispersal. Hybrid traits can be fixed. }\end{array}$ & $\begin{array}{l}\text { Only known in a few crops. Genes } \\
\text { not yet available. }\end{array}$ & $\begin{array}{l}\text { Not yet demonstrated in } \\
\text { transgenic crops. }\end{array}$ \\
\hline Incompatible genomes & Prevents recombination after pollination. & $\begin{array}{l}\text { May not be applicable to crops } \\
\text { that exhibit homologous recombination. } \\
\text { Crops will not produce seed unless } \\
\text { propagated with compatible plants. }\end{array}$ & $\begin{array}{l}\text { Not yet demonstrated in } \\
\text { transgenic crops. }\end{array}$ \\
\hline $\begin{array}{l}\text { Temporal and tissue- } \\
\text { specific control via } \\
\text { inducible promoters }\end{array}$ & $\begin{array}{l}\text { Gene either activated only when product } \\
\text { is } \\
\text { necessary or excised before flowering. }\end{array}$ & $\begin{array}{l}\text { May not be applicable to traits } \\
\text { required throughout the plant's life. } \\
\text { If chemical treatment fails to penetrate } \\
\text { plant tissues, residual levels of transgene } \\
\text { may be present in pollen or seed that } \\
\text { could be outcrossed. }\end{array}$ & $\begin{array}{l}\text { Not yet demonstrated in } \\
\text { transgenic crops. }\end{array}$ \\
\hline Transgenic mitigation & Neutral for crops, but harmful for weeds. & $\begin{array}{l}\text { Does not address gene flow between } \\
\text { crops and may force wild relatives to } \\
\text { extinction. }\end{array}$ & $\begin{array}{l}\text { Not yet demonstrated in } \\
\text { transgenic crops. }\end{array}$ \\
\hline
\end{tabular}

${ }^{a}$ Abbreviations: ER, endoplasmic reticulum; RBF, recoverable block of function. 